\title{
Improving Scientific Communication by Altering Citation and Referencing Methods
}

\author{
Lee Ellis, $\mathrm{PhD}$ (Corresponding author) \\ Department of Anthropology and Sociology \\ University of Malaya \\ Kuala Lumpur, Malaysia \\ Now retired; E-mail: lee.ellis@ hotmail.com
}

Received: December 17, 2021 Accepted: January 24, 2022 Published: February 14, 2022

doi: 10.5296/jsss.v9i1.19548

URL: https://doi.org/10.5296/jsss.v9i1.19548

\begin{abstract}
This article argues that scientific communication can be improved by changing citation and referencing methods in three specific ways. First, include page numbers (or table or figure numbers) in citing sources much more often than is the current practice. Doing so will make it easier to confirm information cited and substantially reduce attribution errors. Twelve specific examples of attribution errors are provided as a way of documenting the need for greater precision in citing sources. Second, make clearer to readers the nature of what is being cited. This can be done by using specific symbols to classify nearly all scientific publications into one of the following three categories: (a) original research, (b) reviews or meta-analyses, or (c) predominantly argumentative or theoretical proposals. Third, the length of the average scientific article can be substantially reduced without losing any ability to document by replacing the conventional citing/referencing method with a method that allows readers to go directly from each citation to the actual referenced material in Google Scholar or Microsoft Academic. Guidelines for this new method are offered.
\end{abstract}

Keywords: scientific communication, citation methods, referencing methods

Appreciation is extended to Drs. Craig Palmer and Anthony W. Hoskin for providing helpful comments on drafts of this article.

\section{Introduction}

The scientific method is the best way yet devised for comprehending the universe, including all of the myriad and complex aspects of human behavior. Nevertheless, as with any other human 
endeavor, the scientific method is not foolproof, especially over the short-term. In the present article, suggestions are offered for improving how scientists communicate with one another in ways that make the information they report more accurately and reliable.

While errors are inevitable, scientists should stive to do everything within reason to keep them at a minimum when reporting their findings. In this regard, a number of studies have documented disturbing numbers of referencing errors (Evans, Nadjari, \& Burchell, 1990; Laua \& Keeb, 1997; Siebers, 2000). While referencing errors most often involve simple misspellings and omissions, others are more consequential, including misrepresentations of findings (Enstrom, 2018; Szajewska, 2018).

In the present article, some misrepresentations of what other researchers have found will be the initial focus of the present report. Twelve specific examples will be given. After documenting these misrepresentations, three suggestions will be offered for how scientific communication in the future can be improved.

\section{(1) Examples of Misrepresentations of Findings by Others}

In the course of doing research primarily for a forthcoming book (Ellis, Palmer, Hoskin, \& Hopcroft, in press), numerous errors involving misrepresentations of findings by others were identified. In other words, one publication cited another publication as having found something that the cited publication did not actually find.

I will demonstrate that most, and perhaps all, of these mistakes would not have been made if specific page numbers (or sometimes specific table or figure numbers) would have accompanied each citation. Before beginning to provide specific examples, let me emphatically state that I have no desire to embarrass or belittle the scientists whose writings will be cited. Also, the twelve examples I will provide are not exhaustive. Instead, they primarily represent those that are the easiest to explain.

Example 1. A report by Flynn (2001, p. 74) on the commission of animal abuse asserted that "male perpetrators predominate". While I have no reason to question this generalization, Flynn cites a study by Felthous and Kellert (1986) as providing support for this conclusion. Actually, the Felthous and Kellert study only sampled males, so a comparison with females was not possible. Had an editor or reviewer of the Flynn manuscript asked for a specific page number to support this assertion, it is almost certain that Flynn would have noticed the mistake and not included this particular citation as providing evidence for his argument.

Example 2. Three studies were cited by Faria, Varela, and Gardner (2018, p. 3) to support their generalization that women have "better-quality sleep" than do men. In fact, only two of the three studies they cited provided support for this statement. The third study actually concluded the opposite. Specifically, van den Berg, Miedema, Tulen, Hofman, Neven, \& Tiemeier (2009, p. 1367) stated that women reported "worse total sleep quality" than did men (emphasis added). If Faria et al. had included a page citation to the van den Berg et al. study, this mistake would have almost certainly been avoided. 
Example 3. According to a review article by Renteria (2012, p. 406), most research has found greater brain hemispheric asymmetry among males than among females. One of the studies cited was authored by Gilmore, Lin, Prastawa, Looney, Vetsa, Knickmeyer, et al. (2007). Renteria stated that the Gilmore et al. study "failed to detect" significant sex differences. Actually, Gilmore et al. did find two significant sex differences in hemispheric asymmetry. Specifically, in Table 3 of their report, Gilmore revealed that males had greater asymmetry in both the frontal and in the occipital regions (both with $\mathrm{p}=.02$ levels of significance). Had Renteria cited Table 3 (or the page on which this table appeared), the likelihood of mis-reporting findings from this study would have been reduced.

Example 4. Raylu and Oei (2002, p. 1014) cited a study by Hraba and Lee (1995) to support the following statement: "Low socioeconomic status, lack of employment, low education levels, and low income have been linked to greater rates of pathological gambling". In fact, the study by Hraba and Lee (1995, p. 114) only found a significant inverse correlation between pathological gambling and years of education. No information was provided by Hraba and Lee pertaining to financial status or family income. Had the journal editor or the reviewers asked Raylu and Oei for page-specific documentation, the citation error would have almost certainly not have been made.

Example 5. According to Peter, Vingerhoets, and van Heck (2001, p. 25), an article by Fischer and Good (1997) reported that males have greater difficulty than females distinguishing people's varying emotional states. While this statement is probably true, the Fischer and Good study actually only sampled males, so a comparison between sexes is not possible. If the journal editor or reviewers had asked Peter and colleagues for a relevant page citation in the Fischer and Good study, they would have realized that this citation provided no support for their statement.

Example 6. Based on a study of sex differences in the body mass index (BMI), Schousboe, Willemsen, Kyvik, Mortensen, Boomsma, Cornes et al. (2003, p. 416) concluded that "mean BMI values are greater among men than among women" and add that this conclusion was also reached in a review article by James, Leach, Kalamara, \& Shayeghi (2001). Actually, James et al. (2001) presented evidence to the exact opposite. Specifically, in Figure 1 of their review, James and associates showed that females had higher average BMI values than did males. There is a high likelihood that the mistaken attribution by Schousboe and associates would have been caught and corrected before publication had they felt obliged to include "Figure 1" as part of their citation.

Example 7. A well-known two-volume book by Maccoby and Jacklyn (1974) was cited by Arneklev, Grasmick, Tittle, \& Bursik (1993, p. 226) to support the following statement "Family-linked variables also have been found to affect criminal behavior in later life." After extensively reading Maccoby and Jacklyn's (1974) two-volume book, I can confidently state that these authors provided no such evidence. Had the publishing journal routinely expected relevant page numbers to be provided, especially in the case of lengthy two-volume books, Arneklev et al. would have almost certainly not made this attribution error. 
Example 8. Another erroneous attribution to the book by Maccoby and Jacklin (1974) is worth noting. Rosario-Hernandez, Rovira-Millán, Santiago-Pacheco, Arzola-Berrios, Padovani, Francesquini-Oquendo (2020, p. 17) stated that Maccoby and Jacklin concluded that males are more impulsive than females. This statement is not true. Maccoby and Jacklin (1974, pp. 100-101) reviewed findings from 37 studies of sex differences in impulsiveness. After doing so, they reported that eight $(21.5 \%)$ of these studies found higher rates for males, $3(8.1 \%)$ found higher rates for females, and the remaining 26 studies (70.3\%) found no significant sex differences. This is another citation error that could have been avoided if Rosario-Hernandez and co-authors would have cited a page number as part of their citation.

Example 9. Rilea, Roskos-Ewoldsen, \& Boles (2004, p. 339) stated that a study by Fischer and Pellegrino (1988) found no significant sex differences in mental rotation ability. Actually, Fischer and Pellegrino only sampled males. Had Rilea and co-author provide a page number to document their statement, they would have almost certainly caught their attribution error before publishing their paper.

Example 10. A meta-analysis by Johnson and Whisman (2013, Figure 1) stated that a study by McKenzie and Hoyle (2008) found males are more likely to ruminate over adverse experiences than females (a finding that is contrary to nearly all other studies of sex differences in rumination). While the article by McKenzie and Hoyle sampled both sexes, it contained no information about sex differences in rumination (personal correspondence with Richard Hoyle, May 13, 2021). If Johnson and Whisman had operated under the guideline of identifying page numbers (or table or figure numbers) to direct readers to the specific evidence whenever possible, they almost certainly would have corrected their error before publication.

Example 11. According to Dreber and Hoffman (2010, p. 11), "in every culture studied, males are more likely to be left-handed (Halpern 2000)". There is no statement in Halpern's (2000) book about sex differences in handedness proportions of each sex in all cultures. The broadest generalization Halpern made about sex differences in handedness was based on a review of findings from just five individual studies. From these five studies, she stated that "left-handedness is statistically associated with being male" (p. 203). Had editors or reviewers of the Dreber and Hoffman manuscript asked them to provide a page number to support their assertion, it is almost certain that the mis-statement about "every culture studied" would have not been part of their report.

Parenthetically, a review of 92 studies of sex differences in handedness by myself and colleagues found that 70 of these studies reporting significantly greater proportions of non-right-handers among males (Ellis, Hershberger, Field, Wersinger, Pellis, Geary et al., 2008, p. 241). The remaining 22 studies found no significant sex differences in handedness.

Example 12. The last example of a misattribution to be presented involved a study of the relationship between birth weight and criminality. Vaske, Newsome, Boisvert, Piquero, Paradis, and Buka (2015, p. 50) cite Fan, Portuguez, \& Nunes (2013) as having reported that low birth weight children were more aggressive and prone to conduct problems than normal birth weight children. Actually, the study by Fan et al. (2013) only sampled low birth weight 
children; and, among these children, it found no significant correlations between delinquency and conduct problems.

To summarize, twelve specific examples of attribution errors made in scientific publications have been described. I could provide more, but, hopefully, these twelve suffice to make a simple point: Attribution errors (a) occur more often than they should, and (b) would be far fewer if citing page numbers (or table or figure numbers) as part of one's citations were the normative practice.

I believe that authors of scientific publications should take the initiative in providing more precise information when citing, and that editors and reviewers should encourage them to do so by asking for more exact documentation anytime a citation appears to be questionable. This is not to say that every citation should have a specific page, table, or figure number accompanying it. Instead, the following simple rules should apply:

1. If the inclusion of a page, table, or figure with a citation can help readers validate what is being attributed to a cited publication, this information should always be provided.

2. On the other hand, if a publication's central theme is being cited (especially if the theme is contained in the publication's title or abstract), then citing a specific page, table, or figure is unnecessary unless an editor or reviewer requests such information.

3. The greater the length of a publication being cited, the more important it is to include page, table or figure numbers when citing it. Citations to entire books, for example, should nearly always have specific pages, tables, or figures provided.

Before moving to another topic, let me reiterate that the purpose of providing specific examples of misattributions was not to cast aspersions on any of the authors involved. It was simply to provide verifiable evidence that erroneous citations are not limited to simple misspelling and reporting the wrong year of publication. To reinforce this point, let me provide two examples of attribution errors that I (and co-authors) have made. In the course of updating a review book on sex difference, I ran across two erroneous citations in our earlier book (Ellis, Hershberger, Field, Wersinger, Pellis, Geary, et al., 2008). Specifically, in the earlier book, we reported that, while most studies have found that females catastrophize over pain more than males, there were two exceptional studies (Ellis et al., 2008, p. 234). Recently, we reread these two studies and found that both of them were mistakenly interpreted (and, it is worth adding, that we did not provide specific page numbers in either case). One of these studies (Osman, Barrios, Kopper, Hauptmann, Jones, \& O'Neill, 1997, p. 594) actually found the opposite of what we stated earlier (thus documenting the usual pattern of females catastrophizing more than males). The other study reported that males "experienced more pain pre-operatively than women but remembered less pain post-operatively" (Eli, Baht, Kozlovsky, \& Simon, 2000, p. 99). In other words, this second study was actually not even directly relevant to pain catastrophizing, contrary to what our earlier book stated. 
Overall, the value of scientific communications is being unnecessarily diminished by a practice that has become far too common, that of failing to provide specific page (or table or figure) numbers when reporting what others have found. From now on, the basic practice should be to provide page-specific information as much as possible, and for editors and reviewers to look favorably on manuscripts in which this is done.

\section{(2) Distinguishing Original Research, Reviews, and Theoretical/Perspective Publications}

As the amount of scientific research continues to accumulate, so too has the importance of meta-analyses as well as other types of literature reviews. However, review publications have come to be cited without being identified as such, and sometimes their citations are mixed in with citations to original research and with publications that provide little more than anecdotes and speculation.

Here is an example: In providing a literature review on sex differences in play behavior among nonhuman primates, Gennuso, Brividoro, Pavé, Raño, \& Kowalewski (2018, p. 2) cites a book chapter by Maestripieri and Hoffman (2012) as providing evidence that male rhesus macaques exhibit more social play behavior than do females of the same species. In fact, this book chapter is itself a literature review. While the focus of this literature review was on rhesus macaques, nowhere does it even mention sex differences in play behavior. This is obviously another example of where the inclusion of a page number would have probably prevented Gennuso and coauthors from making this particular citation error. But, more importantly, it highlights the confusion created by mixing citations to studies that provide new empirical evidence with citations to reviews of studies that provide empirical evidence.

A related point involves the fact that books and articles are sometimes cited as though they offer empirical evidence when all they provide is anecdotal evidence mixed with theoretical arguments. To illustrate, consider the following passage from an article by White, De Sanctis, and Crino (1981:552):

"Western culture teaches young girls to adopt passive, subjective, intuitive, emotional, and dependent qualities, whereas young boys are encouraged to be active, objective, rational, and independent (Killian, 1971). Where society expects boys to be oriented toward power, competition, and prestige, girls are educated to value humanitarian, spiritual, and artistic activities (Miner, 1965)."

Examination of the two sources cited in the above passage leads to the realization that neither source provides any empirical evidence for their arguments. Instead, both Killian (1971) and Miner (1965) only offer argumentative and anecdotal support for their conclusions. In other words, while the quoted passage by White et al. gives one the impression that there is empirical evidence for their arguments, neither of the cited sources provide any such evidence.

Of course, opinions, anecdotes, and especially theoretical arguments can be useful in science, but they should never be conflated with actual empirical evidence. A simple method is needed for distinguishing three basic types of scientifically-relevant publications: Those that provide empirically-based evidence (linked to describing methods used to obtain such evidence), those that are systematic reviews of empirical evidence, and those that are primarily conjecture and 
theoretical arguments. I propose using parentheses - () - to identify original reports of empirical evidence. In the case of reviews (including meta-analyses), square brackets - [] - are recommended when citing them. For indicating that a publication being cited is primarily conjecture or a set of theoretical arguments, squiggly brackets -\{\}$-$ would be used.

Admittedly, there are a few publications (particularly books) that would be difficult to subsume under just one of the above three categories. In these cases, the scientist citing such publications should simply use the symbol that best reflects the reason for the publication being cited. Thus, if a book was cited as a source for the theoretical arguments it presents, the squiggly brackets would be used. But if the book was cited because it provided original empirical evidence, parentheses would be used (and, of course, pages should normally be provided for both).

Lastly, I would recommend always arranging citations in the order in which they were published (rather than being ordered alphabetically according to the first author's last name). This would allow scientists to sometimes cite both literature reviews and subsequent original research reports together. In other words, if a meta-analysis concluded that a certain relationship exists and two subsequent studies confirmed this finding, the review could be cited first in brackets, which would then be followed by citations to the more recent empirical studies in parentheses.

\section{(3) Eliminating Scientific References}

The final suggestion for improving scientific communication may be even more consequential than the first two. Prior to the $20^{\text {th }}$ Century, nearly all references were contained in footnotes located at the bottom of whatever page the citation was made. Over ensuing decades, this practice has been largely replaced by listing references at the end of the manuscript and using what is known as the author(s)/date citation and referencing method. At least in the social and behavioral sciences, the most widely used form of the author(s)/date citation and referencing is some version of the one developed by the American Psychological Association (APA).

Thanks to the advent of online search engines such as Google Scholar and Microsoft Academic, a new method of referencing is possible, and it would almost completely eliminate the necessity of providing any references in scientific publications. Instead of providing references, authors can now simply provide a unique set of words (such as the author's last names) that can be entered into the dialogue box of either Google Scholar or Microsoft Academic. In fact, quite a few of the citations that are used in the APA format can already function this way.

I will refer to the method whereby readers can shuttle directly from citations to online versions of publications (without knowing the compete reference beforehand) as the universal science citation method (or USCM). This method has at least three advantages over the method most commonly used in scientific publications today. First, if adopted, the USCM will reduce the length of the average scientific publication by roughly a third. Second, it will allow readers (including reviewers) to more rapidly check the relevance and accuracy of cited publications. And, third, it will eliminate any need for verifying the accuracy of references as well as the need to assess whether references conform to an exact style format used by a particular journal. 
Parenthetically, several other online search engines for scientific publications are also available, including ISI Science Citation Index, Scopus, Medline, and PubMed. However, these search engines tend to be more specialized in coverage, and some require subscription fees or access codes. Google Scholar and Microsoft Academic cover all fields of science and can be freely accessed instantly by anyone. (While both of these search engines appear to be equally massive in coverage, I personally prefer the formatting of Google Scholar.)

Illustrating USCS Citations. Rather than presenting a set of detailed rules, I will simply provide a few illustrations of the USCM. The first example involves a recently published book by myself and two coauthors. In the conventional APA author(s)/date citation style, this book would be cited as Ellis, Farrington, \& Hoskin, 2019. Using the USCM, the same citation would be Ellis + Farrington + Hoskin 2019. If one copies and pastes this citation into the dialogue box of either Google Scholar or Microsoft Academic, just one publication will appear, thereby making it unnecessary to have the reference for this book at the end of a manuscript that cites it.

Of course, the only basic differences between the conventional citing format and the USCM format is that the latter uses plus signs to separate the last names of authors rather than using commas and ampersands. One reason for the difference is to distinguish the two citing methods. This distinction allows for the fact that certain publications cannot be located in Google Scholar or Microsoft Academic. These include quite a few government documents and some individual chapters that appear in edited books.

Of course, complexities can arise, such as when more than one publication by the same authors appear in the same year. Here is an example: Both an article and a book chapter were published in the same year by Pomerantz and Ruble (1998a \& 1998b) (with no other coauthors), and it so happens that both of these publications are listed in Google Scholar and in Microsoft Academic. How, then, can these two publications be distinguished using the USCM? The method would simply involve identifying one unique key word in the title of each of these two publications. When this is done, I would recommend using a "-" following the authors' names rather than using another plus sign. Thus, the 1998 article by these two authors would be cited as follows: Pomerantz + Ruble - maternal 1998. When this three-word combination is entered into the dialogue box along with the year of publication for either Google Scholar or Microsoft Academic, just one publication appears in the search results.

To cite their book chapter that was published in the same year, the USCM citation would be as follows: Pomerantz + Ruble - multidimensional 1998. This three-word combination leads both Google Scholar and Microsoft Academic to uniquely identify only their book chapter because the term multidimensional is absent from the title of the article that was also published in 1998. (Parenthetically, if page numbers are provided when citing either of these two publications, doing so would further confirm the accuracy of the citation being made.)

Responsibilities when Using the USCM. So, who would be responsible for ensuring the accuracy of each citation if the USCM were adopted? Accuracy in this case means that whenever a citation is copied and pasted into a Google Scholar or Microsoft Academic dialogue box just one publication is identified. The answer is that the manuscript's author(s) 
would be entirely responsible for making sure that this occurs. If it does not, then the author(s) should use an APA style citation with a conventional reference instead.

Because editors and reviewers can quickly shuttle between a USCM citation and the actual publication (or at least the publication's abstract), they can verify any questionable citations more readily. Again, for manuscripts using the USCM, going from a citation in a manuscript to the publication cited would be a more rapid process than with the conventional citation/referencing method.

Advantages of the USCM. By eliminating all (or nearly all) references, the USCM provides a way to substantially reduce the length of scientific publications without diminishing the number of citations that these publication use. In addition, since this method allows editors and reviewers to more readily access cited publications, it should promote citation accuracy (especially if page numbers are included in most citations). Finally, all of the issues having to do with the "proper formatting" and accuracy of references are completely eliminated with the USCM.

Some Qualifying Comments. A major goal of the USCM is to make it possible to seamlessly shuttle between each citation and its corresponding publication without using more words in a citation that is necessary to do so. Accordingly, I would recommend that no more authors be cited beyond two or, at most, three, regardless of how many contributing authors a publication may have. In this regard, the phrase "et al." should not be used in USCM citations, since this phrase could sometimes interfere with the ability of Google Scholar or Microsoft Academic to precisely match a citation with its corresponding publication.

If one wants to show that there are more authors than the number needed to make a precise match between a citation and a publication, one more plus sign can be added in the citation just ahead of the year of publication. For instance, to cite the article by Gilmore, Lin, Prastawa, Looney, Vetsa, Knickmeyer, Lieberman (2007) regarding sex differences in gray matter using the USCM citation, only the first three last names are required, along with the year of publication. But, to indicate that there are authors of this publication beyond the first three, one additional plus sign can be inserted ahead of the year. In other words, the USCM reference would be Gilmore + Lin + Prastawa +2007.

Finally, it is worth stating that some journals (and books) use a numbering citation method rather than an author(a)/date method. In these cases, the USCM can be easily adapted. The adaptation would simply list each the citation numbers along with the corresponding USCM citations for each number at the back of the publication.

\section{Discussion}

The overall objective of this article is to suggest ways of improving scientific communication. Three specific citing and referencing changes were recommended in this regard.

First, provide more precise citations in order to reduce the unfortunate misattributions that scientists are currently making (twelve examples of which were documented along with two of 
my own). Requiring the inclusion of page (or table or figure) numbers with most citations will go far toward reducing these errors.

Second, explicitly distinguish between three main categories of scientific publications. I recommend using normal parentheses to refer to publications that describe new empirical evidence, square brackets for identifying reviews (including meta-analyses) of empirical evidence, and squiggly backets to identify publications that are being cited primarily to offer theoretical or argumentative information.

Third, advances in the internet availability of scientific publications now make it possible to bypass providing nearly all references at the end of scientific publications. Besides shortening the length of scientific communication without losing any information, the proposed USCM (universal science citation method) would eliminate all errors in referencing (such as misspelled names and incorrect dates of publication). Another advantage is that, when readers (including editors and reviewers) want to check a citation, they can shuttle between citations appearing in a manuscript and the pertinent publication with a simple copy-and-paste function.

\section{Conclusions}

A dozen specific examples of published misattributions by others (along with two made by myself) were identified. After doing so, three proposals were offered for improving the citing/referencing process that nearly all scientists currently use: First, reduce the number of attribution errors by providing specific page, table, and figure numbers much more often than is the current practice. Second, distinguish data-based research reports from (a) reviews of research findings and (b) publications that are primarily theoretical or argumentative in nature. Third, eliminate the vast majority of references from scientific publications while still maintaining all citation capabilities by adopting a new method for citing that allows readers to go from each citation directly to whatever publication was cited.

\section{References}

Arneklev, B. J., Grasmick, H. G., Tittle, C. R., \& Bursik Jr, R. J. (1993). Low self-control and imprudent behavior. Journal of Quantitative Criminology, 9, 225-247. https://doi.org/10.1007/BF01064461

Dreber, A., \& Hoffman, M. (2010). Biological basis of sex differences in risk aversion and competitiveness. Stockholm School of Economics. Manuscrito não publicado. Retrieved from http://citeseerx.ist.psu.edu/viewdoc/download?doi=10.1.1.459.331\&rep=rep1\&type=pdf

Eli, I., Baht, R., Kozlovsky, A., \& Simon, H. (2000). Effect of gender on acute pain prediction and memory in periodontal surgery. European Journal of Oral Sciences, 108, 99-103. https://doi.org/10.1034/j.1600-0722.2000.00777.x

Ellis, L., Farrington, D. P., \& Hoskin, A. W. (2019). Handbook of crime correlates, 2nd edition. San Diego, CA: Academic Press. 
Ellis, L., Hershberger, S. L., Field, E., Wersinger, S., Pellis, S., Geary, D. C. ... et al. (2008). Sex differences: Summarizing more than a century of scientific research. New York: Taylor \& Francis.

Ellis, L., Palmer, C., Hoskin, A. W., \& Hopcroft, R. (in press). Handbook of sex differences. New York: Taylor \& Francis.

Enstrom, J. E. (2018). Scientific distortions in fine particulate matter epidemiology. Journal of the American Physician and Surgeon, 23, 15-19.

https://doi.org/10.1177/1559325817693345

Evans, J. T., Nadjari, H. I., \& Burchell, S. A. (1990). Quotational and reference accuracy in surgical journals: A continuing peer review problem. Journal of the American Medical Association, 263, 1353-1354. https://doi.org/10.1001/jama.1990.03440100059009

Fan, R. G., Portuguez, M. W., \& Nunes, M. L. (2013). Cognition, behavior and social competence of preterm low birth weight children at school age. Clinics, 68, 915-921. https://doi.org/10.6061/clinics/2013(07)05

Faria, G. S., Varela, S. A., \& Gardner, A. (2019). The social evolution of sleep: Sex differences, intragenomic conflicts and clinical pathologies. Proceedings of the Royal Society B, 286(1894), 20182188. https://doi.org/10.1098/rspb.2018.2188

Felthous, A. R., \& Kellert, S. R. (1986). Violence against animals and people: Is aggression against living creatures generalized? Bulletin of the American Academy of Psychiatry \& the Law, 14, 55-69.

Fischer, A. R., \& Good, G. E. (1997). Men and psychotherapy: An investigation of alexithymia, intimacy, and masculine gender roles. Psychotherapy: Theory, Research, Practice, Training, 34, 160-170. https://doi.org/10.1037/h0087646

Fischer, S. C., \& Pellegrino, J. W. (1988). Hemisphere differences for components of mental rotation. Brain and Cognition, 7, 1-15. https://doi.org/10.1016/0278-2626(88)90017-6

Flynn, C. (2001). Acknowledging the" Zoological connection": A sociological analysis of animal cruelty. Society \& Animals, 9, 71-87. https://doi.org/10.1163/156853001300109008

Gennuso, M. S., Brividoro, M., Pavé, R., Raño, M., \& Kowalewski, M. (2018\$). Social play among black and gold howler monkey (Alouatta caraya) immatures during intergroup encounters. American Journal of Primatology, 80, e22909. https://doi.org/10.1002/ajp.22909

Gilmore, J. H., Lin, W., Prastawa, M. W., Looney, C. B., Vetsa, Y. S. K., Knickmeyer, R. C., \& Lieberman, J. A. (2007). Regional gray matter growth, sexual dimorphism, and cerebral asymmetry in the neonatal brain. Journal of Neuroscience, 27, 1255-1260. https://doi.org/10.1523/JNEUROSCI.3339-06.2007

Halpern, D. F. (2000). Sex differences in cognitive abilities. Mahwah, NJ: Lawrence Erlbaum Associates. https://doi.org/10.4324/9781410605290

Hraba, J., \& Lee, G. (1995). Problem gambling and policy advice: The mutability and relative 
effects of structural, associational and attitudinal variables. Journal of Gambling Studies, 11, 105-121. https://doi.org/10.1007/BF02107110

James, P. T., Leach, R., Kalamara, E., \& Shayeghi, M. (2001). The worldwide obesity epidemic. Obesity Research, 9(S11), 228S-233S. https://doi.org/10.1038/oby.2001.123

Johnson, D. P., \& Whisman, M. A. (2013). Gender differences in rumination: A meta-analysis. Personality and Individual Differences, 55, 367-374.

https://doi.org/10.1016/j.paid.2013.03.019

Killian, R. A. (1971). The working woman: A male manager's view. New York: American Management Association.

Laua, T. K., \& Keeb, W. D. N. (1997). The quality of citations in major international obstetrics and gynecology journals. American Journal of Obstetrics and Gynecology, 177, 973-975. https://doi.org/10.1016/S0002-9378(97)70303-X

Maccoby, E., \& Jacklin, C. (1974). The psychology of sex differences. Stanford: Stanford University Press. https://doi.org/10.1515/9781503620780

Maestripieri, D., \& Hoffman, C. L. (2012). Behavior and social dynamics of rhesus macaques on Cayo Santiago. In Q. Wang (Ed.), Bones, genetics, and behavior of rhesus macaques (pp. 247-262). New York: Springer. https://doi.org/10.1007/978-1-4614-1046-1_12

McKenzie, K. S., \& Hoyle, R. H. (2008). The self-absorption scale: Reliability and validity in non-clinical samples. Personality and Individual Differences, 45, 726-731. https://doi.org/10.1016/j.paid.2008.07.020

Miner, J. B. (1965). Studies in management education. New York: Springer.

Neuburger, S., Jansen, P., Heil, M., \& Quaiser-Pohl, C. (2011). Gender differences in pre-adolescents' mental-rotation performance: Do they depend on grade and stimulus type? Personality and Individual Differences, 50, 1238-1242.

https://doi.org/10.1016/j.paid.2011.02.017

Osman, A., Barrios, F. X., Kopper, B. A., Hauptmann, W., Jones, J., \& O'Neill, E. (1997). Factor structure, reliability, and validity of The Pain Catastrophizing Scale. Journal of Behavioral Medicine, 20, 589-605. https://doi.org/10.1023/A:1025570508954

Peter, M., Vingerhoets, A. J. J. M., \& Van Heck, G. L. (2001). Personality, gender, and crying. European Journal of Personality, 15, 19-28. https://doi.org/10.1002/per.386

Pomerantz, E. M., \& Ruble, D. N. (1998a). The role of maternal control in the development of sex differences in child self-evaluative factors. Child Development, 69, 458-478. https://doi.org/10.1111/j.1467-8624.1998.tb06202.x

Pomerantz, E. M., \& Ruble, D. N. (1998b). The multidimensional nature of control: Implications for the development of sex differences in self-evaluation. In J. Heckhausen \& C. S. Dweck (Eds.), Motivation and self-regulation across the life span (pp. 159-184): Cambridge University Press. https://doi.org/10.1017/CBO9780511527869.008 
Raylu, N., \& Oei, T. P. S. (2002). Pathological gambling: A comprehensive review. Clinical Psychology Review, 22, 1009-1061. https://doi.org/10.1016/S0272-7358(02)00101-0

Rentería, M. E. (2012). Cerebral asymmetry: A quantitative, multifactorial, and plastic brain phenotype. Twin Research and Human Genetics, 15, 401-413.

https://doi.org/10.1017/thg.2012.13

Rilea, S. L., Roskos-Ewoldsen, B., \& Boles, D. (2004). Sex differences in spatial ability: A lateralization of function approach. Brain and Cognition, 56, 332-343. https://doi.org/10.1016/j.bandc.2004.09.002

Rosario-Hernández, E., Rovira-Millán, L., Santiago-Pacheco, E., Arzola-Berrios, X., Padovani, C. M., Francesquini-Oquendo, S., ... Vélez, E. (2020). ADHD and its effects on job performance: A moderated mediation model. Revista Caribeña de Psicología, 4, 1-25. https://doi.org/10.37226/rcp.2020/01

Schousboe, K., Willemsen, G., Kyvik, K. O., Mortensen, J., Boomsma, D. I., Cornes, B. K., ... Kaprio, J. (2003\$). Sex differences in heritability of BMI: A comparative study of results from twin studies in eight countries. Twin Research and Human Genetics, 6, 409-421. https://doi.org/10.1375/136905203770326411

Siebers R. (2000). The accuracy of references of three allergy journals. Journal of Allergy and Clinical Immunology, 105, 837-838. https://doi.org/10.1067/mai.2000.104935

Szajewska, H. (2018). Evidence-based medicine and clinical research: Both are needed, neither is perfect. Annals of Nutrition and Metabolism, 72, 13-23.

https://doi.org/10.1159/000487375

van den Berg, J. F., Miedema, H. M. E., Tulen, J. H., Hofman, A., Neven, A. K., \& Tiemeier, H. (2009). Sex differences in subjective and actigraphic sleep measures: A population-based study of elderly persons. Sleep, 32, 1367-1375. https://doi.org/10.1093/sleep/32.10.1367

Vaske, J., Boisvert, D., \& Wright, J. P. (2012). Genetic and environmental contributions to the relationship between violent victimization and criminal behavior. Journal of Interpersonal Violence, 27, 3213-3235. https://doi.org/10.1177/0886260512441254

White, M. C., De Sanctis, G., \& Crino, M. D. (1981). Achievement, self-confidence, personality traits, and leadership ability: A review of literature on sex differences. Psychological Reports, 48, 547-569. https://doi.org/10.2466/pr0.1981.48.2.547

\section{Copyright Disclaimer}

Copyright for this article is retained by the author(s), with first publication rights granted to the journal.

This is an open-access article distributed under the terms and conditions of the Creative Commons Attribution license (http://creativecommons.org/licenses/by/4.0/). 